\title{
O ENSINO DE FILOSOFIA PELO PROCESSO DE FILOSOFAR
}

André Santiago Baldan ${ }^{1}$, Genivaldo de Souza Santos ${ }^{2}$

${ }^{1}$ Discente no Programa de Pós Graduação em Educação da Universidade do Oeste Paulista - UNOESTE. ${ }^{2}$ Docente do Programa de Pós-Graduação em Educação da Universidade do Oeste Paulista - UNOESTE. E-mail: andre baldan@hotmail.com

\section{RESUMO}

Este artigo tem como objetivo apresentar uma concepção possível quanto à questão $o$ que é $o$ ensino de Filosofia? Apresentamos a resposta kantiana para esta querela, partindo de obras e comentários sobre Immanuel Kant. Veremos que o ensino de Filosofia aparece como um exercício do pensamento, instigando assim o bom uso da razão. Esta concepção nos auxilia a visualizar objetivos para a disciplina de Filosofia nas salas de aula de ensino médio brasileiras. A preocupação com o tema do ensino de filosofia é relevante visto que tivemos, na história da educação brasileira, a retirada da disciplina de filosofia das escolas na década de 70 e, com a Lei de Diretrizes e Bases 9394/96, tivemos o retorno desta disciplina para o ensino médio. Este trabalho visa então trazer à luz a concepção kantiana para este assunto que é tão vivo na educação brasileira: o que é isso, o ensino de filosofia?

Palavras-chave: Ensino de filosofia. Ensino médio. Filosofia. Filosofar. Kant.

\section{INTRODUÇÃO}

Dentro da história da filosofia temos evidenciado o interesse pela educação em todo seu percurso. Como exemplo temos, na filosofia clássica, a preocupação de Sócrates e de Platão em esclarecer conceitos e propor modelos educativos em seus diálogos; ou, na filosofia medieval, ilustrado pela filosofia escolástica, que deu base para o método utilizado na formação cultural e religiosa de seu tempo; seguindo no percurso histórico da filosofia temos o projeto humanista, da filosofia renascentista, que levava as preocupações filosóficas a centrarem-se no ideal de homem; tendo, ainda, na filosofia moderna, o iluminismo que preocupava-se em tirar o homem das trevas da irrazão.

Tais preocupações da filosofia com a educação permaneceram válidas até o final da primeira metade do século $X X$ onde, devido influencia positivista, as preocupações filosóficas se voltaram a exercícios puramente lógicos, afastando-se das preocupações pedagógicas. (SEVERINO, 1990; DALBOSCO, 2009)

Mesmo sendo um país de pouca tradição filosófica, já tivemos, como aponta Tomazetti (2012), três períodos de destaque no que se refere ao ensino de filosofia. Um primeiro período, que seria o ensino de filosofia no século XX onde se ensinava "A Filosofia” que era "[...] constituída 
por conteúdos como Lógica, Metafísica, História da Filosofia [...]" (TOMAZETTI, 2012. p. 231); e que foi retirada das salas de aula de ensino médio na década de $70^{1}$.

Um segundo período seria dos anos 80 até a Lei de Diretrizes e Bases (LDB) n. 9.394/96 que se caracteriza pela luta do retorno do ensino de filosofia às salas de aula, apontando como objetivo da Filosofia "[...] ensinar o aluno a ser crítico de seu tempo [...]" (TOMAZETTI, 2012. p. 231); com a LDB n. 9.394/96 a conquista veio de forma tímida onde se apontava a importância para alguns conhecimentos transversais.

Atualmente, vivenciamos o terceiro período, caracterizado pela luta da obrigatoriedade da disciplina de Filosofia nas salas de aula do ensino médio brasileiro e pelos desafios do seu ensino no ensino médio. Essa luta foi marcada pelos discursos de que ensinar filosofia é ensinar a filosofar, porém estes mesmos discursos nos levaram a alguns empasses: "o que" ensinar e "como" ensinar Filosofia no contexto escolar? Em parte, estes problemas ocorrem porque não há concepção consensual do que é a Filosofia.

Essa luta para a obrigatoriedade do ensino de Filosofia na matriz curricular do ensino médio obteve êxito com a promulgação da Lei n. 11.684/2008 que alterou a Lei n. 9.394/1996 no artigo 36 (BRASIL, 2008), porém tais problemas continuam vivos em nosso país.

Com esses problemas em foco e cientes de que existe uma pluralidade de concepções quanto ao ensino de Filosofia (FÁVERO, CEPPAS, GONTIJO et al. 2004 ; GELAMO, 2008 e 2009; NOVELI, 2005; SILVEIRA, 2011), executamos um levantamento bibliográfico objetivando a compreensão da concepção kantiana sobre o ensino de filosofia, onde o autor estabelece o ensino de Filosofia como um exercício crítico do pensamento, da razão.

\section{CONCEPÇÃO KANTIANA}

Como já é conhecido de muitos estudantes de Filosofia, e que praticamente se caracteriza como um mantra para alguns professores da disciplina no ensino médio ressoa a famosa frase não se ensina filosofia, se ensina a filosofar! que de certa forma descreve o que seria o ensino de filosofia no âmbito escolar conforme a concepção kantiana. Trata-se, também, de uma expressão assumida como base dos discursos realizados por acadêmicos brasileiros na luta pelo retorno da disciplina de filosofia às salas de aula do ensino médio em nosso país.

\footnotetext{
${ }^{1}$ Em 1961, a partir do Decreto de Lei n. 4.024/61, a filosofia deixou de ser obrigatória no ensino, mas foi com o Decreto de Lei 869/69, regulamentado pelo Decreto $68.065 / 71$, que a filosofia sai definitivamente do currículo do segundo grau, dando lugar para a Educação Moral e Cívica e OSPB. 
Porém o sentido da concepção kantiana acerca do ensino de filosofia, ou mesmo sobre o ensino de um modo geral, não pode ser tão pobremente resumida em uma única frase. Os escritos deste célebre autor acerca da arte de ensinar são relevantes quando refletimos à forma de se ensinar filosofia.

Ramos (2007) indica que Kant possui três aspectos essenciais e que direcionam a visão kantiana acerca da pedagogia, incluindo o que se refere ao ensino de filosofia, esses aspectos seriam:

[...] a) o ideal de perfectibilidade do gênero humano; b) o preceito da Aufklarung do pensar por si mesmo e o exercício crítico da razão, e c) a necessidade da coação como instrumento para a realização dos fins racionais do caráter normativo da conduta humana [...] (RAMOS, 2007. p. 199).

O ideal de perfectibilidade do gênero humano significa que o objetivo final da educação é aperfeiçoar a natureza de cada indivíduo através da orientação de um educador, e este deve ser guiado por um ideal de humanidade, utilizando-se da disciplina com a "[...] função de transformar aquilo que é 'animal' ou selvagem no homem em humanidade" (GELAMO, 2009, p. 42), potencializando o que há de natural nos homens, a aprendizagem e o pensamento. Ou seja, a busca por ser uma pessoa melhor, a busca por preencher lacunas em seu ser torna a educação essencial; sendo esta a responsável pelo aperfeiçoamento dos homens:

É dever do homem educar-se, tornar-se melhor, desenvolver todas as suas disposições e potencialidades, sobretudo, aquelas que dizem respeito à moralidade. Ao agir na formação do indivíduo, a educação porfia em desenvolver $o$ ideal de humanidade que se conquista geração após geração. (RAMOS, 2007. p. 200).

O aspecto do pensar por si mesmo é o segundo aspecto de relevância para a filosofia kantiana visto que se caracteriza pelo exercício crítico da razão, estando esse preceito formulado nas três máximas do juízo de gosto: “A primeira máxima é a do pensamento livre do preconceito, a segunda máxima é aquela do pensamento alargado, a terceira máxima é a do pensamento consequente [...]" (RAMOS, 2007. p. 200).

A primeira máxima remete ao homem ser capaz de pensar autonomamente, a capacidade e habilidade humana de poder pensar com uma razão crítica, livre de coerção, porém guiada por uma mente esclarecida. A segunda máxima refere-se à capacidade do homem de pensar por meio do espírito aberto, fazendo com que a capacidade de pensamento livre se regule e corrija-se. 
Já a terceira máxima, vem de modo a suprir um paradoxo deixado pelas duas capacidades iniciais: um pensamento livre não é coagido, esse pensamento visa rejeitar toda coação possível; já o pensamento alargado mostra-se um pensamento coagido visto que ele visa se autorregular, posicionando-se sempre com a visão do outro. O pensamento consequente vem por tentar solucionar essa querela utilizando do imperativo do dever e do imperativo do direito, onde tais imperativos possibilitam que o homem, sendo coagido de modo externo ou interno, chegue à maioridade onde poderá então fazer o bom uso da razão.

Já o terceiro aspecto, que se refere à "[...] necessidade da coação como instrumento para a realização dos fins racionais do caráter normativo da conduta humana [...]" (RAMOS, 2007, p. 199), esta mais intimamente ligado com a essência da educação, onde a educação ocorre por meio da coação. Utilizando-se de educadores que já passaram pelo processo de educação pela coação e que estão preparados para instruir os jovens e forma-los para a vida. O educador deve preocuparse em criar o jovem para seguir as regras e leis da sociedade em que este individuo se encontra e para que consiga utilizar-se do pensamento livremente, visando a crescimento pessoal e até mesmo o crescimento da humanidade, visto que para Kant o pensamento filosófico não está dado, mas esta em constante construção (GELAMO, 2009).

\subsection{O objetivo da educação}

Como nos indica Ramos (2007), para Kant o objetivo principal da educação é tirar o homem de seu estado de menoridade, o homem deve buscar o esclarecimento, pois essa "é a saída do homem de sua menoridade, da qual ele próprio é culpado" (KANT, 1985, p. 100); o homem deve chegar ao esclarecimento através da conexão de sua autonomia moral, sua cultura e sua autonomia cognitiva: "A educação deve ter por finalidade formar no educando o desejo de andar com as próprias pernas, e fazer com que ele tenha a coragem de fazer uso do seu próprio entendimento." (RAMOS, 2007, p. 201).

Com este objetivo em foco verificamos que o ensino de filosofia deve ocorrer de modo a ensinar o sujeito a filosofar, e não ensinar Filosofia. Filosofia deve ter um papel significativo na vida do jovem, deve ser próxima a ele, deve auxiliar com que este educando possa alcançar a maioridade, capaz de utilizar-se de um pensamento livre do toda coação possível; ou, como nos aponta Gelamo (2009) Kant entende que a filosofia deve ser entendida como ciência da representação, do pensamento e da ação do homem; a filosofia tem de auxiliar no desenvolvimento do uso público da razão, preparar o cidadão para torar-se um critico do 
pensamento, que consiga fazer o bom uso da razão. E diferente do que é desejado, quando ensinamos ao indivíduo conteúdos de Filosofia, desestimulamos este sujeito a executar seus próprios pensamentos, afinal se você tem a possiblidade que outro pense por você não há a necessidade de pensar por si mesmo. Kant indica que o professor deve guiar seu aluno no exercício de pensar por meio de perguntas que remetam aquilo que o mestre deseja ensinar.

A mera erudição do individuo pode transforma-lo em uma pessoa culta, porém limitada no concernente ao uso de seu conhecimento. Sem contar que ao recorrermos ao ensino conteudista corremos o risco de termos mentes "servis, dependentes e tuteladas". O ensino como treinamento prepara os homens para o uso privado da razão, fazendo com que os homens não problematizem as normas a que estão submetidos; esta forma de ensino acaba sendo a desejada pelos governantes pois contribuem para um controle social e a "[...] inibir o homem de fazer uma problematização dos pressupostos doutrinários [...]" (GELAMO, 2009, p. 47) .

O mestre aparece cumprindo um papel parecido com o de Sócrates, numa concepção platônica, tentando trazer à luz o conhecimento ao estudante através de um exercício "erotético" em que o professor, de modo dialógico ou catequético, faz com que o estudante chegue às conclusões desejadas.

A educação assume então o papel de possibilitar a autonomia do homem, fazendo com que ele consiga se livrar das coerções, paradoxalmente através do uso da coerção. O homem, para que possa alcançar um estágio de autonomia, primeiro terá de se submeter à educação coercitiva. Com isso vemos então que o "princípio supremo da educação é a 'cultura da liberdade pela coerção'" (RAMOS, 2007, p. 207) auxiliando o individuo a atingir a autonomia mesmo estando sob uma força coercitiva legítima.

\section{CONSIDERAÇÕES FINAIS}

Pelo que vimos, Kant nos mostra que o ensino de filosofia não ocorre por meio de conteúdos, pois não temos a possibilidade de estudar $A$ Filosofia. A arte de ensinar acaba se caracterizando pela arte de possibilitar ao sujeito que alcance a maioridade, que chegue ao estado de espírito livre e que saiba superar determinadas coerções. Esta arte pode ser sintetizada como a arte de libertar pela coerção, e devido este paradoxo o ensinar se mostra tão problemático e complexo.

Para que não se crie um espírito limitado, porém repleto de erudição, Kant propõe que o ensino de filosofia se dê de modo a fazer das aulas de filosofia uma oficina do uso crítico da razão, 
exercitando o criticismo de seus estudantes. Com isso, justificando sua famosa frase: Não se ensina filosofia, se ensina a filosofar.

O professor assume nesta concepção uma postura de um mestre ignorante, como proposto por Jacques Rancière (2002) onde o professor reconhece sua ignorância junto de seus alunos e os convida para a paciência do pensamento baseado no problemas filosóficos, transformando a sala de aula em uma oficina de pensamento; ou então o professor acaba assumindo uma postura parecida com a de Sócrates e tenta transformar a sala de aula em um diálogo, que por meio de perguntas faz com que os alunos pensem e cheguem ao conhecimento esperado pelo mestre. Para Kant, nossos queridos educandos não vão aprender a pensar simplesmente por serem expostos a uma estrutura de pensamento; os estudantes só terão a capacidade de filosofar se exercitarem a capacidade de pensar; para nosso filósofo só aprendemos a pensar pensando.

Numa tentativa de aproximar essa discussão para as nossas salas de aula, podemos perceber que as Orientações Curriculares Nacionais - Conhecimentos De Filosofia tenta estabelecer uma relação com s concepção kantiana acerca do ensino de filosofia quando propõe que as aulas de filosofia deveriam estimular o filosofar e o pensar (Kant), através do estimulo a um estudo histórico da Filosofia.

A título de exemplo, as OCNs citam a concepção de Silvio Gallo (2012), em que este aponta a filosofia como um "[...] processo e produto ao mesmo tempo; só se pode filosofar pela História da Filosofia, e só se se faz história filosófica da Filosofia, que não é mera reprodução" (BRASIL, 2006, p. 32).

As OCNs objetivam que o ensino de filosofia seja ensinar a filosofar e pensar, ao mesmo tempo o documento procura esclarecer que o ensino de filosofia "[...] não poderia ser apenas a expressão das opiniões dos estudantes, mas deveria estar sustentado na tradição" (TOMAZETTI, 2012, p. 234), vinculando o ato do filosofar à História da Filosofia. Deixando a entender que as aulas de filosofia seriam espaços onde se realizariam atividades e exercícios, estimulando os estudantes a pensarem filosoficamente embasados pela tradição filosófica.

Desta forma o aluno tomaria consciência de seu papel na sociedade, onde ele é agente nos mais diversos níveis sociais, culturais e políticos de sua micro ou macro sociedade. Seria então papel da Filosofia transformar o aluno auxiliando-o nesse processo de ganho de consciência, tornando o aluno capaz de transformar a realidade questionando seu contexto sócio-histórico. 


\section{REFERÊNCIAS}

BRASIL, Ministério de Educação e Cultura. $L D B n^{0}$ 9.394/1996, de 20 de Dezembro de 1996. Estabelece as diretrizes e bases da Educação Nacional. Brasília: MEC, 1996. Disponível em: http://portal.mec.gov.br/arquivos/pdf/ldb.pdf. Acessado em 6 Abr. 2013, às 13 horas e 18 minutos.

BRASIL, Ministério da Educação. Secretaria de Educação Básica. Ciências humanas e suas tecnologias. Brasília, DF, 2006. (Orientações Curriculares para o Ensino Médio; v.3).

Dalbosco, Cláudio A. Por uma filosofia da educação transformada. Anped 2009. Disponível em: http://www.anped.org.br/app/webroot/reunioes/32ra/arquivos/trabalhos/GT17-5336-Int.pdf.

Acessado no dia 03, Mai. 2013,ás 13 horas e 20 minutos.

FAVERO, A. A. CEPPAS, F. GONTIJO, P. E. et al. O ensino de Filosofia no Brasil: um mapa das condições atuais. Caderno Cedes, Campinas, vol. 24, n. 64, p. 257-284, set./dez. 2004. Disponível em: http://www.scielo.br/pdf/ccedes/v24n64/22830.pdf. Acessado em 7 Abr. 2013, às 14 horas e 23 minutos.

GALLO, S. Metodologia do ensino de filosofia: Uma didática para o ensino médio. Campinas - SP: Papirus, 2012.

GELAMO, R. P. O Ensino da filosofia e o papel do professor-filósofo em Hegel. Trans/Form/Ação, São Paulo. v. 31. n. 2., p. 153-166, $2008 . \quad$ Disponível em: http://www2.marilia.unesp.br/revistas/index.php/transformacao/article/viewFile/987/890.

Acessado no dia 6 Mar. 2013, às 16 horas e 58 minutos.

GELAMO, R. P. O ensino da filosofia no limiar da contemporaneidade : o que faz o filósofo quando seu ofício é ser professor de filosofia. Tese (Doutorado em Educação) - Faculdade de Filosofia e Ciências, Universidade Estadual Paulista: Marília, 2009. Disponível em: http://www.marilia.unesp.br/Home/Pos-

Graduacao/Educacao/Dissertacoes/gelamo rp dr mar.pdf. Acessado no dia 13 Mai. 2013, às 22 horas e 13 minutos.

NOVELLI, P. G. A. O ensino da filosofia segundo Hegel: contribuições para a atualidade. Trans/Form/Ação, São Paulo. v. 28. n. 2., p. 129-148, 2005. Disponível em: http://www.scielo.br/scielo.php?script=sci arttext\&pid=S0101-31732005000200009. Acessado no dia 3 Abr. 2013, às 17 horas e 50 minutos.

RAMOS, C. A. Aprender a filosofar ou aprender a filosofia: Kant ou Hegel? Trans/Form/Ação, São Paulo. v. 30. n. 2., p. 197-217, 2007. Disponível em: http://www.scielo.br/pdf/trans/v30n2/a13v30n2.pdf. Acessado no dia 4 Abr. 2013, às 14 horas e 39 minutos.

RANCIÈRE, J. O mestre ignorante: cinco lições sobre a emancipação intelectual. Tradução de Lilian do Valle. Belo Horizonte: Auténtica, 2002. 
TOMAZETTI, E. M. Formação e Arte de viver: o que se ensina quando se ensina Filosofia?. In. BUENO, S. F. PAGNI, P. A. GELAMO, R. P. (org.). Biopolítica, arte de viver e educação. Marília: Oficina Universitária, São Paulo: Cultura Acadêmica, 2012. p. 229-247.

SILVEIRA, R. J. T. Ensino de Filosofia de uma perspectiva histórico-problematizadora. Educação em Revista, Marília, v.12, n.1, p.139-154, Jan.-Jun., 2011. Disponível em: http://www2.marilia.unesp.br/revistas/index.php/educacaoemrevista/article/viewFile/1544/1338 . Acessado em 8 Abr. 2013, às 15 horas e 19 minutos. 